\title{
Generic and professional competences: a pseudo distinction in medical education curriculum
}

\author{
Keywords: graduate profile, institutional, epistemological
}

\section{Presentation}

The medical education curriculum has always been under pressure. Currently, efforts are made for establishing curricula that guarantee an appropriate professional performance according to new conditions. One of the key features is the "graduate profile". This brief paper discusses the situation of the graduate profile of the Medicine Career at a university in Chile, although it can be applied to health professions educations in general. This graduate profile is formed by a set of 6 central competences, grouped in realms of competence focused on professional performance.

It is usual to make distinctions between generic and professional competences. Generic competences are common to all the curricula in this university. It is supposed that different graduate profiles must consider and declare these generic "institutional" competences as well as the professional ones. A question can be asked: How do the generic competences and the professional ones differ in the construction of the graduate profile of the career? Is it necessary to make such distinctions? Four viewpoints will be used to support the idea that clear-cut distinctions are not convenient for curricular design. These viewpoints are: curricular, epistemological, pedagogical and professional.

\section{Curriculum perspective}

A curriculum makes sense and is justified insofar as it is oriented towards the construction of a given professional identity, in this case, that of physician. A physician is characterized by a special form of action in the field of health issues that concern people, communities, societies. The competent exercise does not distinguish between the various components of the action. These distinctions are made expost to improve the comprehension of the performance and, in the case of professional education, to organize the formative processes, understanding that they must be developed in time and according to criteria of progressive increase in complexity, for example. In the process of construction of the students' professional identity, the curriculum proposes articulations that allow the students to construct the respective syntheses, on common bases although with variations due to the individual configurations of each one.

Professional performance (as a practice or as a training process) will always require the presence of the multiplicity of competences that are articulated and configured in a specific way to face the problems that concern the profession in context. ${ }^{1}$ In this way, declarations of competence could not be considered from an excluding logic with strong delimitations and univocal meanings. On the contrary, a competence can be better understood as the statement of a complex of knowledge, procedures, attitudes, experiences, etc., which are articulated for professional performance. Thus, a "professional" competence could not be without reference to a "generic" one: is not morality proper to therapeutic competence? Or does communication not include all forms of interaction between doctor-patient, doctorprofessionals, doctor-community, etc., which would be "professional
Volume 2 Issue I - 2018

\author{
Gustavo Hawes \\ Senior Consultant, Universidad Catolica del Maule, Chile
}

Correspondence: Gustavo Hawes, Senior Consultant, Universidad Catolica del Maule, Chile,Tel +56 992188 594; Email ghawes@ucm.cl; gustavohawes@gmail.com

Received: December 19, 2017 | Published: January 30, 2018

skills" rather than generic? In conclusion, clear-cut distinctions are not the best way to articulate a curriculum. The complexity of medical education and performance requires more a physiological than an anatomical view.

\section{Epistemological perspective}

The epistemological view has two approaches. First, the notion of competence as a construction by the learner in situation, ${ }^{2}$ a vision that denies the analytic division, emphasizing a synthetic view. Second, the movement from the idea of education as a ratio-technical action and assembly process to the idea of education as a communicative process of mutual understanding in a context of problems and knowledges of different kinds, following Habermas' notions of strategic and communicative action. ${ }^{3}$ If professional knowledge is understood only as units of knowledge insert in isolated memory plots, it cannot be put into action: reflection processes are a critical component of professional education. ${ }^{4}$ Thus, it is not reasonable to pretend an integrated professional education from a fractional conception of competence. Considering competences disregarding a classification of generic and professional seems to be a more valid epistemological option.

\section{Pedagogical perspective}

A third argument comes from pedagogy. During the teaching process, multiple interactions exist. A teacher must be alert to different inputs (particularly from the students and the special characteristics of the problems or cases under consideration). At the same time, his/ her communication has to be an integrated discourse, with a central speech and as many variations as required by the circumstances. So, the didactic flow cannot be divided into "generic" and "professional" parts: there is one discourse, a unique one that synthesizes in one communication many components -generic and professional competences included.

\section{Conclusion}

Although distinctions can be made between generic and professional competences, it is only an analytic exercise. Curricular, epistemological and pedagogical arguments support an integrated vision of competences. In brief, it could be said that all competences in a graduate profile are professionals, assuming that a profession is not only a set of procedures to be exercised but a way of being as a professional, a citizen, a person. 


\section{Acknowledgements}

None.

\section{Conflict of interest}

The author reports no conflict of interest. The author alone is responsible for the content and writing of the article.

\section{References}

1. Jonnaert P, Domenico Masciotra, Johanne Barrette, et al. From competence in the curriculum to competence in action. Prospects. 2007;37(2):187-203.
2. Masciotra D, Roth WM, Morel D. Apprendre et enseigner en situation. De Boeck Université, Bruxelles, Germany: Springer; 2008.

3. Habermas J. The Theory of Communicative Action. Volume 2. Lifeworld and System: A Critique of Functionalist Reason. Boston, USA: Beacon Press; 1981.

4. Schön DA. The Reflective Practitioner. San Francisco, USA: JosseyBass; 1983. 245 p. 